\title{
The need for central funding for medical education
}

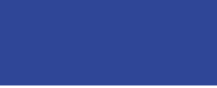

Hyunmi Park

Department of Brain Convergence Research Center, Korea University College of Medicine, Seoul, Korea

"Health Education England exists for one reason only: to support the delivery of excellent healthcare and health improvement to the patients and public of England by ensuring that the workforce of today and tomorrow has the right numbers, skills, values and behaviors, at the right time and in the right place"

"We believe that the most important resource the National Health Service (NHS) has is its people. Without a skilled workforce there is no NHS."

- Statement Health Education England -

After 17 years practicing as a doctor for the British NHS, I arrived at Korea University to hone my robotic surgical skills at the department of surgery through an international fellowship in spring of 2019. The experience of working in the hybrid healthcare system in Korea was very different to the definition of social health care or universal health coverage that Europe enjoys. Many countries around the world, including South Korea have studied the universal health coverage of western Europe, the cradle of socialist care, portraying advanced caring societies. The Korean healthcare system is currently very advanced and the speed of its expansion has been very impressive. The benefits can be seen in the world leading, high life expectancy levels and positive disease outcomes. The uniqueness of the Korean hybrid system of the healthcare coverage from the point of view of a foreigner is interesting. Korea boasts the fastest adaptation of universal health coverage in the last few decades, but this is misleading as the majority of the health care service provided, from primary care all the way to tertiary specialist university hospitals, are privately run. Central government decides on the range of treatments that are to be covered under the national insurance system, all its pricing and percentage of coverage, resulting in the largest insurance monopoly in the hands of the government. Despite this heavy grip, the absolute lack of central funding for education of its healthcare workers is surprising. Hereby, I would like to explain the governmental funding system for the education and training of healthcare workers in the United Kingdom as its core purpose is to maintain a nationwide high quality patient care through the standardization of healthcare professional education.
Received: February 18, 2021 - Revised: February 22, 2021 • Accepted: February 23, 2021 Corresponding Author: Hyunmi Park (https://orcid.org/0000-0002-4134-2213)

Department of Brain Convergence Research Center, Korea University College of Medicine, 73 Goryeodae-ro, Seongbuk-gu, Seoul 02841, Korea

Tel: +82.2.2286.1238 email: hyunmipark@korea.ac.kr
Korean J Med Educ 2021 Mar; 33(1): 45-48 https://doi.org/10.3946/kjme.2021.186 eISSN: 2005-7288

(C) The Korean Society of Medical Education. All rights reserved. This is an open-access article distributed under the terms of the Creative Commons Attribution Non-Commercial License (http:// creativecommons.org/licenses/by-nc/3.0/), which permits unrestricted non-commercial use, distribution, and reproduction in any medium, provided the original work is properly cited. 


\section{Central Medical Education Funding in the United Kingdom and the United States}

The funding of education for health care professionals in socialist Europe is understandable, but even in the pinnacle of capitalism, that is the United States of America, the post graduate education of its healthcare workers is also covered by the national insurance system. In the fall of 2019, a British and an American Surgical program director were invited to the 71st Congress of the Korean Surgical Society held in Seoul. The theme of the session was "How residents were supported through their training programs." The two nations' health care systems are the opposite of each other. One is a purely social tax-based system, free at the point of service, whilst the other lacks an all-encompassing universal healthcare system, unlike most other developed countries. But both nations spend billions of tax payers' pounds and dollars each year in the post graduate medical education of its doctors. During the panel discussion, a local surgical trainer asked the British invited speaker why they felt the tax payer had to contribute to the education of their medical workforce. The answer started with an incredulous: "Does Korea not provide funding to train its doctors?" and was followed by "the funding ensures a uniform and high level of education which will ultimately benefit the safety of all its patients through a high standard of care." The same answer came from the US program director, who echoed that the benefits of funding the postgraduate training of doctors will be ultimately reaped by every US citizen when they become patients, even in the private sector, therefore its central funding of 14 billion dollars per year through Medicare or Medicaid was wholly justified.

\section{Central Medical Education Funding from the NHS budget in the United Kingdom}

The United Kingdom has a population of 66 million and 112,000 doctors (2.8 doctors per 1,000 people). England has a population of 56 million, similar to the 52 million of South Korea. The governmental health budget has grown exponentially since the creation of the NHS seven decades ago in 1947 with healthcare spending increasing to 12 times its original budget even when considering inflation. The share of the public services budget has also increased from $11.2 \%$ to $30.1 \%$. The health budget is managed separately by the four countries that comprise the United Kingdom: England, Scotland, Wales, and Northern Ireland.

\section{Health Education England}

Health Education England is an executive nondepartmental public body of the Department of Health [1]. Its function is to provide national leadership and coordination for the education and training within the health workforce within England. Health Education England believes that for patients to receive the best quality care across the NHS, funding the highest quality education and training at both undergraduate and postgraduate levels is the answer for the creation of world-class health professionals who can work together for the benefit of patients. The vision of Health Education England is to provide the right workforce, with the right skills and values, in the right place at the right time to better meet the needs and wants of patients in the present and in the future. Health Education England's core purpose is the education and training of future healthcare professionals. The expenditure includes 
contribution to salary cost of future health care professionals, direct tuition, and provision of clinical placement experiences with patients.

\section{Educational budget}

The yearly expenditure for Health Education England was over $£ 4,2$ billion (US\$ 6 billion) in 2019 [2], of which $70 \%$ is spent in the education of the medical and dental future workforce, which includes the salaries of all trainees. The governmental tariff covers funding for all direct costs involved in delivering education and training by the provider [3]. The cost can be divided into the following areas:

Benefits received by the trainees include their salary, course fees, and expenses that are required to achieve professional registration. The training-related educational time away from clinical practice is covered by nontraining physicians employed by the hospital and includes study leave and time for clinical exams, mandatory in-course feedback, and assessments. For students or trainees who are rotating in district general hospitals away from the central university hospital, accommodation is also provided. Pastoral and supervisory support and health and wellbeing are also funded centrally.

Funding received by the trainers includes the monetarization of direct staff teaching time within a clinical placement. Most clinicians are clinical educators but a few will undergo training to be appointed educational supervisors with extra funding. The attendance of "training the trainer courses" is also funded.

Hospitals receive funding to allow adequate training provisions which include the building of teaching and student facilities, with access to library services. Administration and infrastructure costs and staff training and development relating to their educational role are also funded.

The total cost for trainees who receive a salary in the NHS was $£ 2.2 b n$ (US\$3bn) [2], where the salary of the trainee accounted for $45.9 \%$ of the cost and the hospital that provided the training placement received $54.1 \%$ to train the trainee. Teaching is incorporated into the specialist's weekly activities as part of their job contract. The average working week of a specialist doctor is 40 hours divided into 10 programmed activity (PA) sessions. One PA comprises 4 hours between 7 AM and 7 PM or 3 hours of premium time. The week is normally made up of 7.5 PA sessions of direct clinical care, which includes ward rounds, clinics, surgery, and patient administration and 2.5 PA sessions of supporting professional activities. Teaching is included here together with audit, appraisal, research, training, clinical governance, and clinical management activities. This means, that teaching is a planned, agreed, contracted and paid Programmed Activity. Teaching is paid, as it is regarded to be as important as direct patient care.

For education to take place in a clinical setting, the time expenditure on any given clinical activity will inevitably be longer when a trainee is being trained. For example, a lower gastrointestinal endoscopy list (sigmoidoscopy and colonoscopy) that is performed by a specialist will be able to cater up to eight patients in a half-day session, but a specific training list will only have four patients to allow proper supervised education to take place. This halving of clinical cases will have an impact on the costing received by the hospital which is replaced by the educational fund from Health Education England.

Table 1 shows that for each trainee, the teaching hospital will receive both the salary cost of the trainee and an additional amount to cover the teaching cost of the hospital which is more than double the salary cost [4]. The costings of a procedure performed in the hospital do not include the training cost as this is paid for separately through Health Education England. 
Hyunmi Park: Central funding for medical education

Table 1. Total Cost for Trainees in the National Health Service for 2016/2017 [4] (in US\$ millions)

\begin{tabular}{|c|c|c|c|c|c|c|}
\hline \multirow{2}{*}{ Variable } & \multicolumn{2}{|c|}{ Salary cost } & \multicolumn{2}{|c|}{ Placement cost } & \multicolumn{2}{|c|}{ Total cost } \\
\hline & US\$ millions & $\%$ & US\$ millions & $\%$ & US\$ millions & $\%$ \\
\hline Medical and dental trainees & $1,290.0$ & 45.5 & $1,548.2$ & 54.5 & $2,838.2$ & 93.6 \\
\hline Other salaried professions & 100.3 & 52.0 & 92.6 & 48.0 & 192.9 & 6.4 \\
\hline Total salaried & $1,390.3$ & 45.5 & $1,640.8$ & 54.1 & $1,640.8$ & 100.0 \\
\hline
\end{tabular}

Health Education England exists to support the delivery of excellent healthcare and health improvement to the patients and public of England through the training of its future workforce. From the selection of every single foundation doctor (intern), resident, and fellow and the placement into every post throughout the country to the standardized education, supervision, and support, every single of the 65 million British population is able to trust the specialist doctor from whom they are receiving care. This is the reason that British patients do not go beyond their neighborhood to register with a primary care physician and do not search further than their designated secondary or tertiary center. Many of my previous patients refused to be referred to tertiary units and preferred their local hospital, despite the distance being under one hour by car. The patient concentration phenomenon that I have experienced in Seoul, coming from all corners of South Korea, may be due to the diminished trust in the standardization of health care provision and especially in the skills of the health care professionals. Central funding of health care training is known to result in standardized and high-quality care, which ultimately leads to improved patient outcomes and more importantly, the universal trust in the profession by the population.

For a nation priding itself in reaching universal health coverage in the shortest period such as South Korea, the central funding of the education of its healthcare professionals ought to also be high in the list of its spending priorities, to ensure a high and uniform level of care and protect the safety of its people. The decision to receive such funding should be accompanied by an agreed and robust method of distributing and managing such an educational budget.

\section{ORCID:}

Hyunmi Park: https://orcid.org/0000-0002-4134-2213

Acknowledgements: None.

Funding: No financial support was received for this study. Conflicts of interest: No potential conflict of interest relevant to this article was reported.

Author contributions: All work was done by Hyunmi Park.

\section{References}

1. National Health Service. Health Education England. https:/www.hee.nhs.uk/about. Accessed December 15, 2020 .

2. National Health Service, Health Education England. Health Education England annual report and accounts 2019-20. Leeds, UK: Health Education England; 2019.

3. National Association of Clinical Tutors. A guide to the funding \& accountability of medical education: an explanatory document to help leaders, business managers and finance staff understand the new tariff structures for medical education. Bletchley, UK: National Association of Clinical Tutors; 2016.

4. Health Education England. Proposed changes to currencies for education and training placements. Leeds, UK: Health Education England; 2017. 